\title{
A study on effects of organizational structure on performance of research organizations
}

\author{
Seyed Mahdi Mousavi ${ }^{{ }^{*}}$, Rahmatollah Jadidi ${ }^{\mathrm{b}}$ and Habibollah Javanmard ${ }^{\mathrm{a}}$
}

${ }^{a}$ Public Management, Islamic Azad University, Arak Branch, Arak, Iran

${ }^{b}$ University Professor of Medical School of Arak, Arak, Iran

'Islamic Azad University, Arak Branch, Arak, Iran

\section{H R O N I C L E}

Article history:

Received July 18, 2012

Received in revised format

10 November 2012

Accepted 15 November 2012

Available online

November 292012

Keywords:

Organizational performance

Research centers

Performance measurement

\begin{abstract}
A B S T R A C T
Organizational structure plays an important role on survival of any business units and it is important to understand different factors influencing it. In this paper, we present an empirical study to learn the effects of three parameters including formality, concentration and complexity on organizational performance. The proposed study of this paper is implemented for one of research-based organization located in city of Qom, Iran. There were 120 employees working for this organization and the proposed study of this paper has selected a sample of 100 people, designed, and distributed a questionnaire among them. The proposed study uses two methods of regression analysis as well as structural equation modeling to study the impacts of three variables on organizational performance. The results show that there are some positive and meaningful relationship between formality and concentration from one side and organizational performance from the other side. In addition, there is a meaningful and negative relationship between complexity and organizational performance. The results of structural equation modeling are also consistent with the results of structural equation modeling.
\end{abstract}

(C) 2013 Growing Science Ltd. All rights reserved.

\section{Introduction}

For many years, research and development have been the basis for adding value to organizations. In fact, many fastest growing leading edge technology firms have gained most of their financial success through developing new products and services. Developing new ideas helps most of high technology firms gain more market share and survive in today's competitive market. Kaplan and Norton (1992, 1996) are believed to be first who emphasized on relative importance of intangible assets. Intangible assets normally include human resources who are the primary sources of research and development.

Kaplan and Norton (1992) developed the idea of balanced score card (BSC) and for measuring the performance of 12 companies in USA. The purpose of BSC was to replace and make some changes on the traditional performance evaluation frameworks, which primarily concentrated on financial 
indexes to calculate more complete and efficient evaluation of organizational performance evaluation. They argued that financial figures were not the primary key success of business development and presented some non-financial perspective for performance measurement. These aspects of traditional model include customer, internal business processes and employee's growth and learning, so that performance evaluation model can achieve a good balance and efficiency in comparison compared with the past. These aspects are necessary for perception and implementation of a suitable performance evaluation system and formation of a general set of organization performance indexes for strategic investigation of all objectives and activities of a firm. There are four perspectives in BSC as follows,

1. Financial aspect: this perspective considers how firms take advantage of their strategic activities.

2. Customer aspect: this perspective concentrates more on issue that organizations should benefit of their inherent and available resources for the distinction compared with their competitors.

3. Internal business process aspect: this includes all the strategic activities in a particular firm performed to meet stockholder and customer's needs. General process is initiated by perception of customer's requirements and the operational and sale processes are executed next.

4. Growth and learning aspect: if business units wish to retain permanent activity and development, they must always rely on constant growth and innovation.

Kaplan and Norton (1992) explained that organizations had to focus on some goals such as promotion of employee's capabilities and abilities, persuasion, information system performance, etc. This aspect includes three main criteria including employee continuity, employee satisfaction, and efficiency. Firms and organizations must build performance evaluation indexes by these three criteria. Performance indices need to be chosen unbiased and measurable associated with organizational objectives. Index selection is essential for investigating the necessary industry performance, since it enhances efficiency of manufacturing operations and creates significant advantages by precise investigation of these indexes. Performance key indexes should be studied for achievement of strategic objectives in every four BSC perspectives. Relationships among various perspectives of BSC are indicated in Fig. 1.

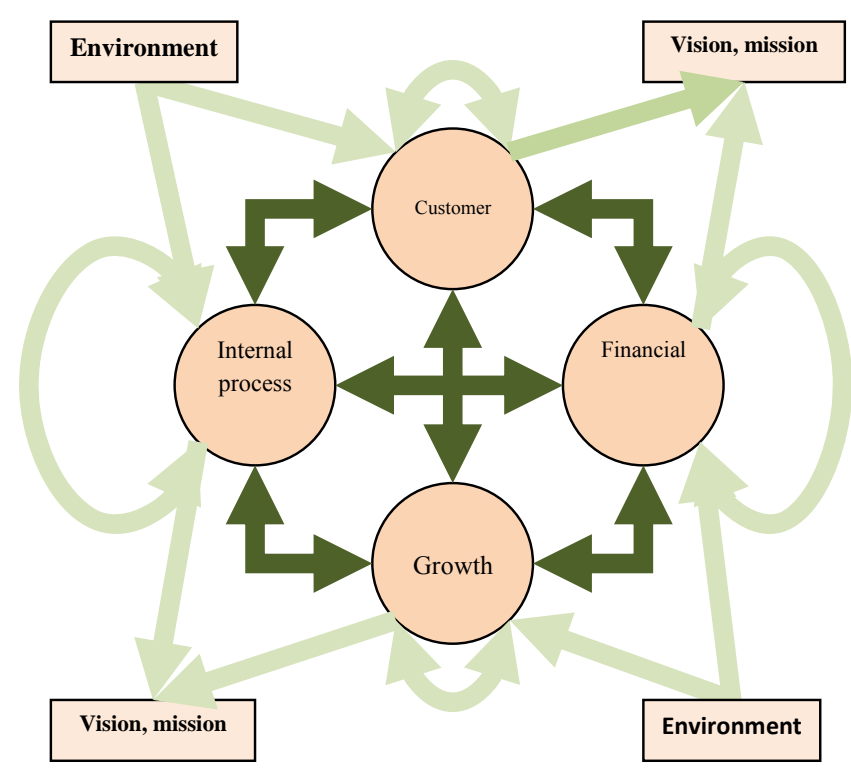

Fig.1. Relationships among various BSC perspectives 
Kaplan and Norton (1996) believed that BSC includes could influence relations among various indexes in selected aspects. Other researchers similarly stated experimental evidences in support of causal relations among various BSC perspectives. These relationships point to the dependence among financial and non-financial indexes. A structured BSC method should incorporate mutual relationships among different perspectives and measuring indexes of these aspects (Wang et al., 2010). Tseng (2010) developed the fuzzy form of BSC. Grigoroudis et al. (2012) used the idea of BSC for healthcare industry using the idea of multiple criteria decision making to rank the relative important of four perspectives. Huang et al. (2011) developed strategic measurement and improvement for the biopharmaceutical firm based on the idea using the BSC hierarchy.

Momeni et al. (2010) evaluated the performance of society assurance organization using a combination of fuzzy data envelopment analysis and BSC. Seyedhosseini et al. (2011) extracted leanness criteria by employing the concept of BSC. Yuksel and Dag deviren (2010) implemented the fuzzy analytic network process (ANP) for BSC in a case study for a manufacturing firm. According to Keramati et al. (2013), organizational commitment plays an essential role in business development especially in educational system. They studied the relationship between six personal characteristics of employees of Azad University in province of Arak, Iran. They designed and distributed a questionnaire among experts who were involved in educational systems. The questionnaire consisted of various questions in Likert scale and there were six independent variables including age, gender, educational background, marital status, job experience and salary. They studied the relationship of these six items with organization commitment. The results of the survey indicated that marital status was the most influential factor on organizational commitment followed by educational background and job experience. Based on the results of the survey, they concluded that those employees who could get more experience and maintain a good educational background would more likely to stay with a firm than young employees.

\section{The proposed model}

In this paper, we study the effects of three factors of formality, concentration and complexity on BSC performance measurement of research based organizations. There are three hypotheses as follows,

1. There is a meaningful relationship between formality and performance measurement in research based organizations.

2. There is a meaningful relationship between concentration and performance measurement in research based organizations.

3. There is a meaningful relationship between complexity and performance measurement in research based organizations.

Fig. 2 shows details of the framework of the proposed model of this paper.

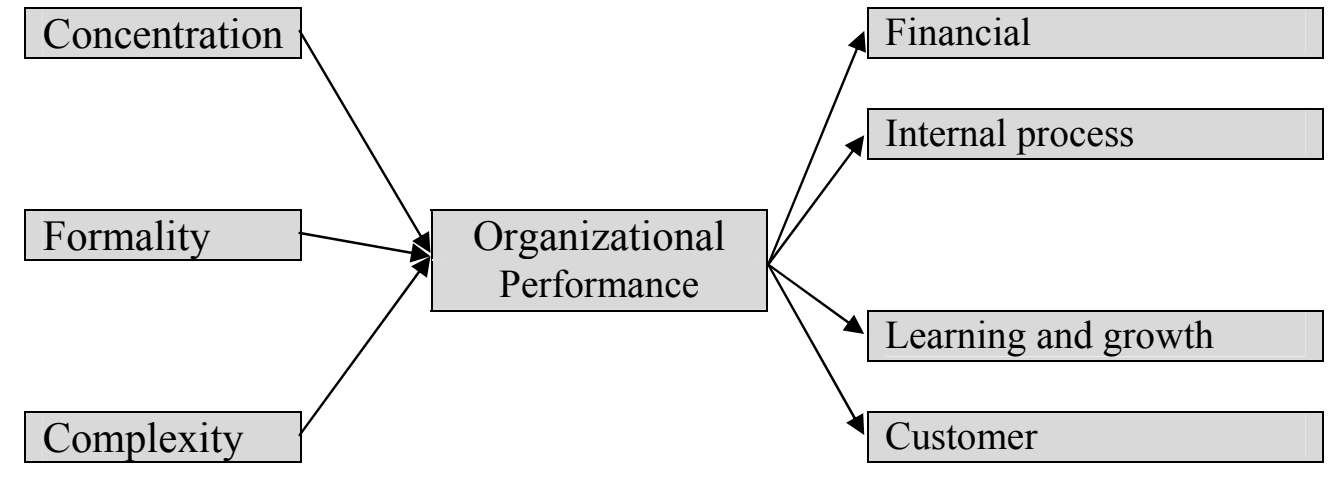

Fig. 2. The framework of the proposed model 
The proposed study of this paper is implemented for one of research-based organization located in city of Qom, Iran. There were 120 employees working for this organization and the proposed study of this paper has selected a sample of 100 people, designed, and distributed a questionnaire among them. The study uses a regression model as follows,

$O P=\beta_{0}+\beta_{1} F M+\beta_{2} C O M+\beta_{3} C O N+\varepsilon$,

where $O P$ represents organizational performance, $F M, C O M$ and $C O N$ represent formality, complexity and concentration, respectively. In addition, $\beta_{0}, \beta_{1}, \beta_{2}$ and $\beta_{3}$ represent parameters, which are estimated through implementation of ordinary least square technique.

\section{The results}

The proposed study of this paper used Pearson correlation test to investigate the relationships. The results Pearson correlation test between organizational structure and organizational performance has yielded a value of 0.49 with the P-value of 0.000 . This means there is positive and meaningful relationship between these two items. Table 1 demonstrates various aspects of organizational structure with organizational performance.

\section{Table 1}

The relationship between organizational components with organizational performance

\begin{tabular}{llll}
\hline Organizational components & Pearson correlation & P-value & Result \\
\hline Formality & 0.56 & 0.000 & Confirmed \\
Complexity & -0.43 & 0.000 & Confirmed \\
Concentration & 0.51 & 0.000 & Confirmed \\
\hline
\end{tabular}

As we can observe from the results of Table 1, there are some positive and meaningful relationship between formality and concentration from one side and organizational performance from the other side. In addition, there is a meaningful and negative relationship between complexity and organizational performance. The results of regression analysis on Eq. (1) is as follows,

$$
\begin{array}{lcccc}
\multicolumn{1}{c}{O P=1.358+0.247 F M} & -0.206 C O M+0.472 C O N+\varepsilon \\
\text { t-student } & (4.303) & (12.931) & (4.741) & (7604) \\
\text { P-value } & 0.000 & 0.000 & 0.000 & 0.001
\end{array}
$$

As we can observe from the results of Eq. (2), organizational performance has meaningful relationships with formality, complexity and concentration since all t-student values are statistically meaningful when the level of significance is one percent. In addition, an increase of one unit on formality will increase organizational performance by 0.247 and an increase of one percent in concentration will increase organizational performance. However, an increase of one percent in complexity will reduce organizational performance by -0.206 .

We have also used structural equation modeling to study the relationship between different components of this study and Fig. 3 demonstrates the results of our investigations. As we can observe from the results of the implementation of structural equation modeling, all statistics remain within acceptable limits, which mean we can accept the results. The results are also consistent with what we have found using regression technique. Concentration impacts positively (0.42) on organizational performance, formality also influences positively $(0.35)$ on organizational performance while complexity negatively $(-0.25)$ influences organizational performance. Organizational performance 
also impacts positively on financial $(0.43)$, internal process $(0.76)$, learning and growth $(0.68)$ and customer (0.47), respectively.

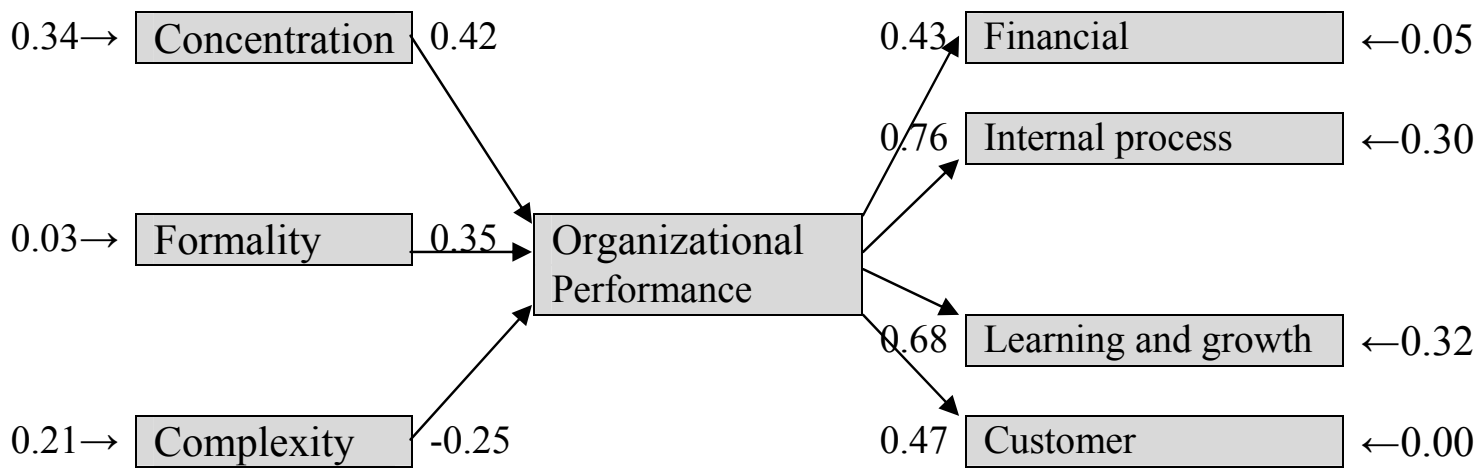

Chi-square $=2.3, \mathrm{NFI}=0.97, \mathrm{NNFI}=0.95, \mathrm{CFI}=0.92, \mathrm{GFI}=0.94, \mathrm{AGFI}=0.97$

Fig. 3. The results of structural equation modeling in standard form

\section{Conclusion}

We have presented an empirical study to learn more about the effects of three parameters including formality, concentration and complexity on organizational performance. The proposed study of this paper has implemented for one of research-based organization located in city of Qom, Iran. There were 120 employees working for this organization and the proposed study of this paper has selected a sample of 100 people, designed, and distributed a questionnaire among them. The proposed study has implemented two methods of regression analysis as well as structural equation modeling to study the impacts of three variables on organizational performance. The results have indicated that there were some positive and meaningful relationship between formality and concentration from one side and organizational performance from the other side. In addition, there was a meaningful and negative relationship between complexity and organizational performance. The results of structural equation modeling are also consistent with the results of structural equation modeling .

\section{Acknowledgment}

The authors would like to thank the anonymous referees for constructive comments on earlier version of this paper, which contributed to quality of the paper.

\section{References}

Grigoroudis, E., Orfanoudaki, E., \& Zopounidis, C. (2012). Strategic performance measurement in a healthcare organization: A multiple criteria approach based on balanced score. Omega, 40, 104119.

Huang, H. C., Lai, M.C., \& Lin, L. H. (2011). Developing strategic measurement and improvement for the biopharmaceutical firm: Using the BSC hierarchy. Expert Systems with Applications, 38, 4875-4881.

Kaplan, R. S. \& Norton, D. P. (1992). The balanced scorecard - measures that drive performance, Harvard Business Review, 70(1), 71-79. 
Kaplan, R.S. \& Norton, D.P. (1996). The balanced scorecard: translating strategy into action, Harvard Business School Press, Boston, MA.

Keramati, M.A., Horri, M.S., \& Afzalopoor, S. H. R. (2013). A study on effects of personal characteristics on organizational commitment. Management Science Letters, 3(1), 345-350.

Momeni, M., Khodaei, S., \& Bashiri, M. (2010). Evaluation of performance of society assurance organization by used of combination FDEA and BSC. Journal of Industrial Management, 3, 137152.

Seyedhosseini, S.M., Taleghani, A.E., Bakhsha, A., \& Partovi, S. (2011). Extracting leanness criteria by employing the concept of Balanced Scorecard. Expert Systems with Applications, 38, 1045410461.

Tseng, M.L. (2010). Implementation and performance evaluation using the fuzzy network balanced scorecard. Computers \& Education, 55, 188 -201.

Yuksel, I., \& Dag deviren, M. (2010).Using the fuzzy analytic network process (ANP) for Balanced Scorecard (BSC):A case study for a manufacturing firm. Expert Systems with Applications, 37, 1270-1278. 